\title{
A review of 7 years of complaints in an inner-city Accident and Emergency Department
}

\author{
M. T. HUNT \& M. E. GLUCKSMAN
}

Accident and Emergency Department, King's College Hospital, Denmark Hill, London

\section{SUMMARY}

In 7 years between $1982-88,122$ complaints were lodged against the Accident and Emergency department of King's College Hospital. A high percentage mentioned more than one aspect per complaint. Commonest were those regarding attitude $(37.7 \%)$, missed diagnosis $(36.6 \%)$, waiting time $(32.8 \%)$, cursory examination $(\mathbf{1 4 . 7 \% )}$ and poor communication $(\mathbf{1 1 . 5 \% )}$. These causes of complaint are amenable to improvement. Training in interpersonal skills may reduce complaints of attitude. A high index of suspicion for the unusual and careful examination of patients would reduce complaints of missed diagnosis. Sufficient medical and nursing staff would reduce waiting time and improvements in communication with patients would keep this aspect to a minimum. Complaint investigation can be time consuming, when dissatisfaction is expressed explanations at the time of presentation by senior staff members may head-off a formal complaint.

\section{INTRODUCTION}

This article examines complaints received by the Accident and Emergency (A\&E) department at King's College Hospital from January 1982 to January 1989. The average daily attendance for the department is 223 patients and the total number of patients seen during the period of investigation was 602886 .

Correspondence: Mr Martin T. Hunt, Senior Registrar, Accident and Emergency Department Royal Essex County Hospital, Brighton, BN2 3EW U.K. 


\section{PATIENTS AND METHODS}

Complaints analysed were those indicating dissatisfaction with $A \& E$ as receivedz by letter, telephone call and personal attendance. Complainants coming directly to: the A\&E department were redirected to the hospital administrator where the $\Rightarrow$ complaint could be formally lodged as laid down in the DHSS Circular HC(88)37? and in accordance with the District complaints policy.

Complaints were identified by reviewing Camberwell Health Authority records $\frac{\overline{\bar{c}}}{\bar{*}}$ and files in the A\&E Department containing details of all formal complaints in the $e_{\stackrel{\Phi}{\Phi}}^{\circ}$ period examined.

The nature of the complaints, their timing, patient details and nature of the $\vec{\circ}$ incident, were examined and the results and final outcome analysed.

\section{RESULTS}

A total of 122 complaints were received representing 1 complaint per 4941 new patients or 1 complaint per 21 days.

The number of complaints from 1982 to 1986 (Table 1) is fairly constant, the years 1987 and 1988 show a marked reduction in the complaint numbers however the relative proportions of causes for complaints, i.e. waiting time, wrong diagnosise etc., remains the same.

The frequency of complaints is constant throughout the year, any variationn being proportional to attendance figures.

Slightly more complaints, $76(62.4 \%)$, occur between Mondays and Thursdays than in the latter part of the week, this is in keeping with our attendance figures, $\bar{\Phi}$ more patients attending on these days.

Distribution by hour of incidents causing complaints did not reflect the activity in the department during the day. Fifty-nine per cent of patients attended the department between 9 a.m. and 5 p.m., $41 \%$ attended in the remaining $16 \mathrm{~h}$. Slightly more complaints, $55 \%$, occurred during the out of hours period, 5 p.m. to 9 a.m.

Patients and relatives make up the majority of complainants and although male $\stackrel{3}{3}$. and female attendances are almost equal there were significantly more complaintsô

Table 1 Complaints per year:

\begin{tabular}{rc}
\hline Complaints & Year \\
\hline $22(18 \cdot 0 \%)$ & 1982 \\
$21(17 \cdot 2 \%)$ & 1983 \\
$19(15 \cdot 6 \%)$ & 1984 \\
$30(24 \cdot 6 \%)$ & 1985 \\
$18(14 \cdot 7 \%)$ & 1986 \\
$6(4 \cdot 9 \%)$ & 1987 \\
$6(4 \cdot 9 \%)$ & 1988 \\
\hline
\end{tabular}


Table 2 Complainants

\begin{tabular}{lr} 
(1) Relatives & $49(40 \cdot 1 \%)$ \\
(2) Patients & $41(33 \cdot 6 \%)$ \\
(3) Solicitors & $13(10 \cdot 7 \%)$ \\
(4) Community groups & $7(5.7 \%)$ \\
(5) Friends & $7(5.7 \%)$ \\
(6) Community Health Council & $3(2.4 \%)$ \\
(7) General Practitioner & $2(1.6 \%)$ \\
\hline
\end{tabular}

from women, 55 to 35 men. Men and women, however complained equally on their own behalf for grievances against themselves (Table 2).

The age distribution of patients involved in complaints parallels that of patients attending and is not a reflection of a group of patients more prone to complain.

Often a complainant mentioned more than a single problem, $50 \%$ of the complainants expressed dissatisfaction with more than one aspect of their A\&E attendance. Thus there were 207 complaints from 122 individuals.

The causes of complaints can be separated into 12 categories (Table 3 ).

(1) Complaints about the attitude of medical staff were included in $37.7 \%$ of complaints. Rudeness and an apparent lack of sympathy for ill patients together with an 'off-hand', 'flippant', 'arrogant' and 'dismissive manner' were the main complaints levelled at medical staff by patients and relatives.

(2) Missed diagnosis caused $36 \cdot 1 \%$ of complaints (Table 4 ):

Missed fractures, the commonest diagnostic errors, include cases where the diagnosis was either not made or the severity not appreciated. No one fracture in our series seemed more likely to be missed, examples ranging from metacarpal fractures, to fractures of long bones, skull and vertebral bodies. In almost half these cases the presentation was delayed more than $36 \mathrm{~h}$.

The gynaecological missed diagnoses comprise two cases of ectopic pregnancy, two cases of threatened abortion which became inevitable and one case of genital herpes.

Table 3 Nature of complaints

Per cent of total (122)

\begin{tabular}{lrr} 
(1) Attitude problems & 46 & $(37 \cdot 7 \%)$ \\
(2) Missed diagnosis & 44 & $(36 \cdot 1 \%)$ \\
(3) Waiting time & 40 & $(32 \cdot 8 \%)$ \\
(4) Cursory examination & 18 & $(14 \cdot 7 \%)$ \\
(5) Poor communication & 14 & $(11 \cdot 5 \%)$ \\
(6) Triage related & 10 & $(8 \cdot 2 \%)$ \\
(7) RTA fees (pre 1985) & 8 & $(6 \cdot 5 \%)$ \\
(8) No transport home & 8 & $(6 \cdot 5 \%)$ \\
(9) Physical environment & 8 & $(6 \cdot 5 \%)$ \\
(10) Lack of privacy & 4 & $(3 \cdot 3 \%)$ \\
(11) Miscellaneous & 4 & $(3 \cdot 3 \%)$ \\
(12) No follow-up arrangements & 3 & $(2 \cdot 5 \%)$ \\
\hline
\end{tabular}

Complaints $\quad 207$ 
Table 4 Missed diagnosis

\begin{tabular}{lc}
\hline Missed fractures & $18(41 \%)$ \\
Gynaecological & $5(11 \cdot 4 \%)$ \\
Visceral & $5(11.4 \%)$ \\
Soft tissue & $5(11.4 \%)$ \\
C.N.S. & $4(9.1 \%)$ \\
Diabetic & $2(4.5 \%)$ \\
Cardiac & $1(2 \cdot 2 \%)$ \\
Other & $4(9.1 \%)$ \\
\hline Total & 44 \\
\hline
\end{tabular}

Complaints classified as visceral relate to delay in the diagnosis of perforated $\vec{\sigma}$ duodenal ulcer, the unrecognized severity of gastroenteritis, pain from an acute $\frac{\mathbb{D}}{3}$ back injury diagnosed as gastritis, renal colic diagnosed as a urinary tract infection $\frac{3}{\infty}$. and two cases of appendicitis which were thought to be mesenteric adenitis.

Incorrect soft tissue diagnosis related to urticarial rash and whiplash injury; two $\vec{\nabla}$ cases related to wound complications and one case of a scrotal injury of unrecognized $\stackrel{ }{2}$ severity.

Complaints regarding the central nervous system involved meningitis, subarachnoid haemorrage, a stroke, and a patient with sudden loss of consciousness $\stackrel{\widehat{\rho}}{\supset}$ who had sustained an earlier head injury.

The one cardiovascular system complaint was that of a patient with atypica $\stackrel{\oplus}{-}$ chest pain who later died of a cardiac arrest.

There were four cases where the A\&E department was accused of misseg diagnosis when the patient usage of the department was thought to be inappropriatè.

(3) Waiting time featured in $40(32.8 \%)$ complaints, patients waiting for beds to become available and for specialist opinions constituted two thirds of this group. The remaining third relates to patients waiting for investigations initiated from A\&E.

(4) Eighteen complaints $(14.7 \%)$ were filed where the patient felt their examination by the doctor was cursory and inadequate. In all these cases there was also a complaint about the doctors attitude or there was a missed diagnosis.

(5) Fourteen $(11.5 \%)$ complaints consisted of lack of communication between $\frac{0^{3}}{3}$ staff and patients and relatives, referral to other specialties and waiting for transport $\delta$ home.

(6) Ten $(8 \cdot 2 \%)$ complaints were a direct result of a formal system of triage in the $\frac{9}{2}$ department. All cases were found to have been appropriately triaged except one $\frac{D}{0}$ patient with terminal carcinoma of the bronchus who waited an inappropriate length of time before being seen by a casualty officer.

(7) Fees for patients brought to hospital by ambulance following a road traffic $N$ accident (R.T.A.) generated $8(6.5 \%)$ complaints, 7 of these resulted from an $\omega$ ignorance of the ruling, one patient was sent the demand for the fee in error, having made his own way to the accident department. These fees are no longer $\stackrel{\bullet}{C^{\circ}}$ collected.

(8) Of the $8(6.5 \%)$ complaints regarding arrangements for transport home, six 
were felt to have made inappropriate use of the ambulance in the first place for minor injuries and did not warrant ambulance transport home. The remaining two were made by patients waiting for ambulance transport when the department was very busy.

(9/10) The A\&E Department at King's College Hospital was designed at the beginning of the century for one third of the patients who now use it. Complaints about the physical environment, related to the cramped conditions, lack of privacy, poor ventilation and lack of provision of refreshments.

$(11 / 12)$ Three complaints $(2.5 \%)$, resulted from patients being sent home without either GP or district nurse follow up. The remaining miscellaneous $4(3.3 \%)$ cases were of a minor administrative nature.

Time from incident to complaint

Three quarters of the complaints were made within a month of the incident, over $60 \%$ within the first 2 weeks and $89 \%$ within 6 months.

A little over $50 \%$ of complaints were answered within the time guidelines set down by the DHSS and in accordance with local policy. Over $75 \%$ of complaints were answered within 2 months. The remaining complaints either involved legal action or the complainant was not satisfied with the reply and a formal interview was arranged.

\section{Medico-legal cases}

Since 1982, 194 claims have resulted in medico-legal action against King's College Hospital, $16(8 \%)$ of these were against the A\&E department. To date this represents $13 \%$ of A\&E complaints: 4 cases have been dropped, 3 are pending, 2 have had damages awarded and 1 lost his claim for negligence. The remaining 6 complainants are in the process of taking legal advice. There is therefore a 1:8 chance of a complaint against the A\&E department proceeding to a medico-legal claim.

\section{DISCUSSION}

Nationally 12 million patients attend A\&E departments every year, representing $20 \%$ of the population. In urban areas with high population densities and in areas of high social deprivation, as defined in the Jarman Index, the attendance figures to A\&E departments per catchment population per year may be higher. The catchment population of King's College Hospital is 225000. The average yearly total attendance figures in the A\&E department are 82000 patients. Thus the equivalent of $36 \%$ of the catchment population attend the $A \& E$ department at King's College Hospital every year. This work-load coupled with departmental design limits and staffing constraints inevitably generates some dissatisfaction 
with the A\&E service provided. Patients and relatives tend to seek an explanation, an apology or compensation for what they see as inadequacies in the service.

Complaints over the last 7 years show a slight rise to 29 in 1985 which coincides with the introduction of a system of triage. During 1985 complaints about $\stackrel{\mathrm{D}}{\mathrm{D}}$ waiting time increased slightly however those of missed diagnoses decreased.

The numbers of complaints in 1987-88 has dropped and we consider this reduction to be a real one although it takes time for complaints to be received. Our own results show $90 \%$ of patients or relatives will have complained within $6 \frac{\bar{\sigma}}{\bar{c}}$. months. Five years is the time suggested by Richmond and Evans (1989) for this $\overrightarrow{\mathrm{\sigma}}$ process.

It is likely the reduction in complaints is due to two factors (1) the appointment, $\stackrel{\infty}{\vec{\circ}}$ in 1986, of a senior registrar (SR) to the accident and emergency department and at the same time and; (2) refining the system of triage, the relative contributions of $\vec{\omega}$ each is difficult to interpret.

The drop due to an SR appointment may improve the service due to (1) better 3 . SHO supervision and (2) to increased manpower facilitating patient through-put. $\stackrel{\infty}{-}$

The drop due to a refined system of triage, although allowing patients to be seen $\vec{v}$ in order of priority, has the disadvantage of removing an experienced nurse from 9 the main department. In practice the deployment of a nurse to triage out-weighs $\overrightarrow{-}$ this disadvantage. Although the number of complaints has dropped since 1985 the proportion of each complaint category remains the same.

These possible reasons for reduction in complaints add weight to the argument $\overrightarrow{0}$ for adequate numbers of medical and nursing staff in A\&E departments. Overadi $\stackrel{\bullet}{-}$ our results reveal that complaints are proportional to work-load. A noteworth exception however is in the decrease in complaints over the weekend when the are fewer doctors on duty. An explanation may be that the A\&E department is used more in a primary-care role at this time and patients with less urgent problems are willing to wait for treatment.

It is worrying to note that although the numbers of complaints has decreased in the last few years, the number proceeding to medico-legal investigation has increased. This may be due to greater publicity about litigation over the last few years or imply higher expectations of service by the public.

\section{RECOMMENDATIONS}

(1) Training in interpersonal skills may reduce 'attitude' problems and complaint generating situations should be high-lighted in $A \& E$ training.

(2) Doctors and nurses in A\&E should have a high index of suspicion for the $\tilde{N}$ unusual. Patients should be carefully examined and consideration given for those $\widetilde{O}$ problems frequently mis-diagnosed.

(3) Staffing should be sufficient to prevent long waiting times reducing the stresses on staff and patients. All patients should be triaged by a trained nurse.

(4) Improved communication and a more holistic approach to patient care may improve patient/doctor interaction. Promotional leaflets to explain the function of 
the A\&E department and why patients are waiting may be useful in keeping patients informed.

(5) Some indication of dissatisfaction may be given by the patient or relative at the time of attendance. An explanation and apology should be given if possible at that time by a senior member of the department. The work involved in investigating complaints is considerable and any means to reduce complaint numbers should be explored.

\section{CONCLUSION}

The main causes of complaints, staff attitude, waiting time and missed diagnosis are all remediable. Only by unbiased examination of the circumstances of the complaint can work practices be evaluated and the service provided improved.

\section{REFERENCES}

Department of Health and Social Security. (1988) Health services managenent: clinical complaints procedure' Department of Health and Social Security. (Health Circular: HC (88) 37) Guidelines.

Richmond P. W. \& Evans R. C. (1989) Complaints and litigation - three years experience at a busy accident and emergency department 1983-5. Health Trends 21, 42-5. 